\title{
Hepatite $C$ na década de 1980: resgate de casos das antigas hepatites "não $A$ e não $B$ " de um serviço de hepatologia na Amazônia, Brasil
}

\section{Hepatitis $C$ in the 1980s: case review of former non-A and non-B hepatitis from a hepatology service in the Brazilian Amazon}

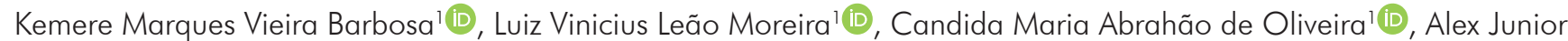
Souza de Souza ${ }^{1}$ (D), Heloisa Marceliano Nunes' (D), Manoel do Carmo Pereira Soares' (D), Lourdes Maria Garcez ${ }^{1,2}$ (D)

1 Instituto Evandro Chagas/SVS/MS, Belém, Pará, Brasil

2 Universidade do Estado do Pará, Belém, Pará, Brasil

\section{RESUMO}

OBJETIVO: Descrever a frequência de infecção pelo vírus da hepatite C (VHC) em amostras de soro de pacientes diagnosticados como hepatite "não-A e não-B", atendidos em um instituto de pesquisa da Amazônia, entre 1982 e 1988. MATERIAIS E MÉTODOS: Pesquisa descritiva, transversal e retrospectiva, incluindo 396 amostras de soro, preservadas a $-20{ }^{\circ} \mathrm{C}$ e testadas para anticorpos lg $\mathrm{G}$ anti-VHC por ELISA. As amostras eram de pacientes de ambos os sexos, variando de 1 mês a 85 anos de idade, oriundos dos municípios de Belém e Ananindeua, Pará, Brasil. Para amostras anti-VHC reagentes, investigou-se a presença de RNA viral e, nos detectados, procedeu-se sequenciamento e genotipagem. RESULTADOS: Anticorpos anti-VHC foram detectados em 10,9\% (43/396) dos soros examinados. O RNA do VHC foi detectado em 55,8\% (24/43) dos soros reagentes. Para 33,3\% (8/24) dessas amostras, foi possível a distinção dos genótipos 1 (75,0\%; 6/8) e 3 (25,0\%; 2/8), com a confirmação de dois subtipos (1 b e 3a). CONCLUSÃO: Apesar das limitações, pelo longo tempo de armazenamento das amostras (três décadas), foi possível detectar e caracterizar o VHC em soros oriundos de biobanco, revelando a circulação de dois genótipos e dois subtipos virais à época: o genótipo 1, detectado na maioria das amostras genotipadas e, na atualidade, exibindo maior resistência a fármacos que os demais genótipos conhecidos; e o genótipo 3, menos frequente na amostra do estudo, associado a maior virulência. A análise permitiu identificar linhagens do VHC, favorecendo estudos futuros para elucidar aspectos evolutivos associados à resistência e à virulência desse patógeno.

Palavras-chave: Vírus da Hepatite C; Diagnóstico Molecular; Perfil Genotípico; Epidemiologia.

\begin{abstract}
OBJECTIVE: To describe the frequency of Hepatitis C virus (HCV) infection in serum samples from patients diagnosed with "non-A and non-B" hepatitis attended at an Amazonian research institute between 1982 and 1988. MATERIALS AND METHODS: Descriptive, cross-sectional, and retrospective research including 396 serum samples preserved at $-20{ }^{\circ} \mathrm{C}$ and tested for anti-HCV lgG antibodies by ELISA. The samples were from patients of both sexes, ranging from 1 month to 85 years old, from Belém and Ananindeua, Pará State, Brazil. For reactive anti-HCV samples, the presence of viral RNA was investigated, and sequencing and genotyping were conducted in those detected. RESULTS: Anti-HCV antibodies were detected in $10.9 \%$ (43/396) of the sera examined. HCV RNA was detected in 55.8\% (24/43) of the reagent sera. For 33.3\% (8/24) of these samples, it was possible to distinguish genotypes $1(75.0 \% ; 6 / 8)$ and $3(25.0 \% ; 2 / 8)$, with the confirmation of two subtypes (1b and 3a). CONCLUSION: Despite the limitations, due to the long storage time of the samples (three decades), it was possible to detect and characterize HCV in biobank sera, revealing the circulation of two genotypes and two viral subtypes at the time: genotype 1, detected in most genotyped samples and currently exhibiting greater drug resistance than other known genotypes; and genotype 3, less frequent in the study sample, associated with higher virulence. The analysis allowed the identification of HCV strains, favoring future studies to elucidate evolutionary aspects associated with the resistance and virulence of this pathogen.
\end{abstract}

Keywords: Hepatitis C Virus; Molecular Diagnosis; Genotypic Profile; Epidemiology.

\author{
Correspondência / Correspondence: \\ Kemere Marques Vieira Barbosa \\ Instituto Evandro Chagas/SVS/MS, Seção de Hepatologia \\ Av. Almirante Barroso, 492. Bairro: Marco. CEP: 66093-020 - Belém, Pará, Brasil - Tel.: +55 (91) $3214-2077$ \\ E-mail: kemerebarbosa@iec.gov.br
}




\section{INTRODUÇÃO}

A infecção pelo vírus da hepatite $\mathrm{C}(\mathrm{VHC})$ ainda constitui grave problema de saúde pública no Brasil e no mundo'. Segundo a European Association for the Study of the Liver (EASL), 71 milhões de pessoas estão infectadas cronicamente pelo $\mathrm{VHC}$ ao redor do mundo, e, nas Américas, estima-se que sejam 7 milhões $^{2}$. Desse número, apenas 25\% foram diagnosticadas 2,3 . No Brasil, entre 1,4 e 1,7 milhão de indivíduos podem estar infectados com o $\mathrm{VHC}^{4}$.

As hepatites virais afetam cronicamente cerca de 325 milhões de pessoas em todo o mundo, sendo que $95 \%$ dos infectados desconhecem sua doença e menos de $1 \%$ têm acesso ao tratamento ${ }^{3}$. A hepatite C é geralmente assintomática, com sinais e sintomas ocorrendo principalmente em estágios avançados da doença ${ }^{4}$. Milhões de pessoas podem progredir de forma lenta para cirrose, descompensação hepática e hepatocarcinoma, tornando essa infecção a causa mais frequente de transplante hepático no mundo ${ }^{1,2,4}$. Apenas $10 \%$ dos pacientes desenvolvem icterícia e menos de 20\% possuem sintomas inespecíficos mais graves, como anorexia, náuseas, vômitos, diarreia, mal-estar, dor abdominal, entre outros ${ }^{5}$.

A transmissão ocorre por meio do compartilhamento de objetos pessoais; seringas e agulhas para uso de drogas injetáveis ${ }^{4}$. $\bigcirc$ diagnóstico tardio da hepatite C contribui para a transmissão da doença e sua alta mortalidade ${ }^{1,3}$.

A hepatite C foi primeiramente observada em doadores de sangue na década de 1980 e caracterizada como hepatite "não A e não B" (HNANB) ${ }^{6}$. Denominada inicialmente como "hepatite pós-transfusional não-A e não-B de transmissão parenteral", a etiologia da hepatite C foi elucidada em 19897. O agente da hepatite C foi classificado na família Flaviviridae, gênero Hepacivirus e espécie Hepacivirus $C$, depois do advento de técnicas moleculares ${ }^{8}$.

Dessa forma, estudos retrospectivos sobre frequência de infecção pelo VHC são importantes fontes de reconhecimento da história natural da doença9 ${ }^{9}$, mas são escassos na Região Amazônica brasileira. Esse paralelo temporal também permite a comparação do perfil epidemiológico dos doentes em dois cenários distintos, antes e após a aquisição dos testes de diagnóstico e do tratamento da doença. Este estudo objetiva descrever a prevalência da infecção pelo $\mathrm{VHC}$ em amostras de soro de pacientes diagnosticados como HNANB, entre 1982 e 1988, provenientes da Amazônia Legal.

\section{MATERIAIS E MÉTODOS}

Estudo descritivo, transversal, retrospectivo, que utilizou 396 amostras sorológicas provenientes do biobanco da Seção de Hepatologia (SAHEP) do Instituto Evandro Chagas (IEC), Secretaria de Vigilância em Saúde (SVS), Ministério da Saúde (MS), armazenadas a $-20{ }^{\circ} \mathrm{C}$ por mais de 30 anos. Essas amostras foram coletadas, no período de 1982 a 1988, de pacientes atendidos com quadro clínico compatível com HNANB aguda e, com marcadores sorológicos negativos para hepatites $A$ e B, de um total de 2.223 casos consecutivos atendidos na Região Amazônica. Para a coleta dos dados clínicos, demográficos e laboratoriais, foram realizadas pesquisas em livros de registro e fichas epidemiológicas dos casos triados.

As 396 amostras de soro foram testadas para pesquisa de anticorpos anti-VHC lgG, pelo método ELISA, com kits comerciais de quarta geração (DIA. PRO Diagnostic Bioprobes ${ }^{\circledR}$, San Giovanni, Itália), obedecendo os procedimentos e interpretação indicados pelos fabricantes. $\bigcirc$ volume reduzido das amostras impossibilitou o uso de aparelho automatizado no diagnóstico sorológico.

resultado final das amostras foi dado em densidade óptica, obtida pela leitura em espectrofotômetro (Leitora de Microplaca BIOTEK EL800). O valor de cut-off desse teste foi calculado adicionando-se o valor 0.350 à média da absorbância dos controles negativos. Os resultados que excederam o valor de cut-off acrescido de $20 \%$ foram considerados reagentes. Os valores de densidade óptica abaixo do valor de cut-off menos $20 \%$ foram considerados não reagentes. Os resultados com densidade óptica até $20 \%$ acima ou abaixo do valor de cut-off foram caracterizados como inconclusivos.

As amostras que apresentaram resultados inconclusivos foram submetidas ao teste sorológico para detecção do anti-VHC, pelo método ELISA, com kits comerciais de terceira geração (ORTHO VHC Version 3.0 ${ }^{\circledR}$ ELISA Test System, New Jersey, EUA). As interpretações dos resultados se deram pelo espectrofotômetro (Leitora de Microplaca BIOTEK EL800); para a determinação de cut-off, acrescentou-se a constante 0,600 ao valor da média de absorbância dos controles negativos.

Amostras reagentes para anti-VHC foram selecionadas para detecção e caracterização molecular do VHC. $O$ VHC-RNA foi pesquisado por técnica de RT-qPCR e RT-PCR. A extração do RNA foi processada de forma automatizada (equipamento m24sp/m2000rt - Abbott $^{\circledR}$ ), com volume final de $60 \mu \mathrm{L}$. Após a extração, foram realizadas a amplificação e a detecção do VHC-RNA, com o uso do kit comercial Abbott RealTime VHC (Abbott $\left.{ }^{\circledR}, E U A\right)$, segundo as instruções do fabricante. A detecção do VHC-RNA foi realizada com o sistema TaqMan ${ }^{\circledR}$ utilizando primers e sondas TaqMan ${ }^{\circledR}$ específicos. $O$ ensaio Abbott RealTime VHC apresenta uma linearidade de 12 a 100.000.000 Ul/mL. O RNA das amostras, extraído por método automatizado (equipamento $\mathrm{m} 24 \mathrm{sp} / \mathrm{m} 2000 \mathrm{rt}-\mathrm{Abbott}^{\circledR}$ ), foi utilizado para a síntese de cDNA, feita com primers randômicos (IDT) sob as seguintes condições de termociclagem: 15 min a $25^{\circ} \mathrm{C}$, seguido de $1 \mathrm{~h}$ a $37^{\circ} \mathrm{C}$ e incubação final de $95{ }^{\circ} \mathrm{C}$ por $15 \mathrm{~min}$.

CDNA das amostras foi utilizado em ensaios de RT-PCR para amplificação parcial das regiões NS5B e 5'UTR do VHC, subsequente sequenciamento nucleotídico e análise filogenética para genotipagem do vírus. A amplificação da região NS5B foi desenvolvida por ensaios de hemi-nested RT-PCR para produção de um fragmento de 382 pares de base. Durante as etapas de $1^{\circ}$ round de PCR, $5 \mu \mathrm{L}$ de CDNA de 
cada amostra foram acrescidos aos iniciadores $\operatorname{Pr} 3$ (5'TATGAYACCCGCTGYTTTGACTC3') e Pr4 (5' GCNGARTAYCTVGTCATAGCCTC3') e submetidos à condição de termociclagem, conforme descrito por Morice et al. ${ }^{10}$ e Sandres-Sauné et al. ${ }^{11}$. As reações de $2^{\circ}$ round de PCR foram realizadas com os iniciadores Pr3 e Pr5 (5' GCTAGTCATAGCCTCCGT 3') nas condições de ciclagem ${ }^{10,11}$. Para a região 5'UTR, foi realizado nested RT-PCR, visando a amplificação de um fragmento de 230 pares de base (pb) do gene que codifica a região 5'UTR. Foram utilizados $5 \mu \mathrm{L}$ de cDNA, na reação de PCR, usando os iniciadores PTC 1 (5'CGTTAGTATGAGTGTCGTGC3') e NCR2 (5'ATACTCGAGGTGCACGGTCTACGAGACCT3') nas condições de ciclagem ${ }^{12}$. A segunda PCR foi realizada com os iniciadores PTC3 (5'AGTGTCGTGCAGCCTCCAGG 3') e NCR4 (5'CACTCTCGAGCACCCTATCAGGCAGT $3^{\prime)}$ nas mesmas condições de ciclagem da primeira PCR.

A detecção dos amplicons foi realizada em gel de agarose a 1\% (Ultra Pure Agarose-Invitrogen, Espanha), SYBR $^{\circledR}$ Safe DNA Gel Stain (Invitrogen, EUA) e marcador de peso molecular (50 pb DNA Ladder, Invitrogen, USA). A visualização e a captura das imagens foram feitas com equipamento de fotodetecção (TFX-35M GIBCO BRL W Transluminador). Foram consideradas positivas as amostras que apresentaram produtos de amplificação com tamanho próximo ao esperado, $230 \mathrm{pb}$ para a região 5'UTR e 382 pb para a região NS5B.

Os produtos amplificados foram purificados com o kit EXO/SAP-IT (GE Healthcare Bio-Sciences, Buckinghamshire, Reino Unido) e, posteriormente, sequenciados, nos sentidos senso e antissenso, com os primers $\operatorname{Pr} 3$ e $\operatorname{Pr} 5$ para a região NS5B e PTC3 e NCR4 para a região 5'UTR, respectivamente, utilizados junto com o kit BigDye ${ }^{\circledR}$ Terminator v3.1 Cycle Sequencing (Applied Biosystems, Vilnius, Lituânia) no sequenciador automático ABI 3500 (Applied Biosystems). Todas as reações foram desenvolvidas de acordo com as orientações dos fabricantes. As sequências obtidas foram editadas e alinhadas no programa Geneious v8.1.3 e, juntamente com as sequências dos diferentes genótipos e subgenótipos do VHC, disponibilizadas no GenBank. As árvores filogenéticas foram construídas usando o método Neighbor-Joining e modelo Kimura 2-parâmetros no programa MEGA v7.

$\bigcirc$ teste do qui-quadrado $\left(\chi^{2}\right)$ da homogeneidade serviu para comparar as proporções das variáveis de interesse (manifestações clínicas, sexo, idade, procedência) em duas ou mais populações (infectados pelo $\mathrm{VHC}$ ou não infectados pelo $\mathrm{VHC}$ ). A análise de resíduos mostrou como as diversas proporções da tabela de contingência contribuem para o valor final do $\chi^{2}$ calculado ( $p=0,05)$. Foi utilizado o programa BioEstat v5. $0^{13}$.

Obedecendo à Resolução No 466, de 12 de dezembro de 2012, do Conselho Nacional de Saúde/MS ${ }^{14}$, o presente projeto foi aprovado pelo Comitê de Ética em Pesquisa em Seres Humanos do IEC/SVS/MS, sob Parecer de Aprovação n 1.947.422, em 3 de março de 2017.

\section{RESULTADOS}

Os pacientes tinham idades variando de 1 mês a 85 anos, com média de 29,9 $( \pm 17,9)$ e mediana de 26 anos, encontrando-se, a maioria, entre 21 e 30 anos de idade $(28,0 \%)$. A proporção de homens e mulheres foi semelhante, embora ligeiramente maior a frequência para o sexo masculino $(55,3 \%)$. Todas as amostras eram de pacientes da zona urbana, dos municípios de Belém e Ananindeua, Região Metropolitana do estado do Pará. $\bigcirc$ maior número de portadores de HNANB era residente do bairro do Marco $(11,1 \%)$. Dentre os registros dos pacientes que continham informações sobre ocupação, a maior frequência era de estudantes (22,2\%). Contudo, houve prejuízos na interpretação dos resultados pela alta frequência de campos vazios, p. ex. "não informado". Os principais destaques sobre o perfil demográfico dos doentes constam na tabela 1 .

As manifestações clínicas relatadas pelos pacientes, que buscaram a SAHEP/IEC na década de 1980 e que receberam o diagnóstico de HNANB, foram coletadas de 322 das 396 fichas preenchidas e disponíveis, destacando-se: colúria (180/322; 55,9\%), icterícia (161/322; 50,0\%), febre (148/322; 46,0\%), vômito $(106 / 322 ; 32,9 \%)$, mialgia $(93 / 322 ; 28,9 \%)$, mal-estar $(90 / 322 ; 27,9 \%)$, anorexia $(76 / 322 ; 23,6 \%)$, náuseas (76/322; 23,6\%) e diarreia $(41 / 322 ; 12,7 \%)$.

Os indivíduos positivos para anti-VHC residentes em Belém eram oriundos, em sua maioria, do bairro do Marco (6/38; 15,8\%). A figura 1 destaca os bairros com dois ou mais casos de anti-VHC reagentes $(23 / 38$; $60,5 \%)$.

No município de Ananindeua, a maioria das amostras positivas $(3 / 5 ; 60,0 \%)$ era de pacientes que residiam no bairro da Cidade Nova (Figura 2).

Anticorpos anti-VHC foram detectados em 10,9\% (43/396) das amostras, com prevalência semelhante entre sexos. As frequências mais elevadas de anti-VHC foram observadas em adultos com mais de 20 e menos de 60 anos de idade, destacando-se a faixa etária de 51 a 60 anos. Não houve significância estatística entre sexo e faixa etária quando correlacionados com a presença de anticorpo do VHC. Foi possível detectar a presença do RNA viral em 55,8\% (24/43) das amostras sororreagentes ao VHC. Para os resultados positivos, segundo sexo e faixa etária, não houve significância estatística quando correlacionados à infecção pelo VHC (Tabela 2).

Por meio da genotipagem, foram encontrados dois genótipos (1 e 3), subtipos 1 b e $3 a$, respectivamente, em oito (33,3\%) dos 24 RNA detectados (Quadro 1). 0 cladograma desenvolvido para as amostras de $\mathrm{VHC}$ teve por base o alinhamento de sequências da região NS5B (382 pb). Três amostras agruparam com sequências do genótipo 1, subtipo 1 b, e uma agrupou com o genótipo 3, subtipo 3a (Figura 3).

A análise filogenética da região 5'UTR não permitiu a determinação dos subtipos do VHC, pois os amplicons dessa região apresentaram sequências com um número limitado de bases nucleotídicas ( $<230$ pb), o que impossibilitou a inferência das relações filogenéticas. 
Tabela 1 - Distribuição dos pacientes diagnosticados com HNANB, segundo sexo, faixa etária, procedência e ocupação, de 1982 a 1988, em Belém e Ananindeua, estado do Pará, Brasil

\begin{tabular}{|c|c|c|}
\hline Variáveis & $N=396$ & $\%$ \\
\hline \multicolumn{3}{|l|}{ Sexo } \\
\hline Masculino & 219 & 55,3 \\
\hline Feminino & 177 & 44,7 \\
\hline \multicolumn{3}{|l|}{ Faixa etária (anos) } \\
\hline$\leq 10$ & 63 & 15,9 \\
\hline $11-20$ & 75 & 19,0 \\
\hline $21-30$ & 111 & 28,0 \\
\hline $31-40$ & 57 & 14,4 \\
\hline $41-50$ & 40 & 10,1 \\
\hline $51-60$ & 23 & 5,8 \\
\hline$\geq 61$ & 27 & 6,8 \\
\hline \multicolumn{3}{|l|}{ Procedência } \\
\hline Belém & 349 & 88,1 \\
\hline Ananindeua & 47 & 11,9 \\
\hline \multicolumn{3}{|l|}{ Bairros } \\
\hline \multicolumn{3}{|l|}{ Belém } \\
\hline Marco & 44 & 11,1 \\
\hline Marambaia & 23 & 5,8 \\
\hline Nazaré & 21 & 5,3 \\
\hline Umarizal & 20 & 5,0 \\
\hline Pedreira & 19 & 4,8 \\
\hline Telégrafo & 18 & 4,5 \\
\hline Jurunas & 16 & 4,0 \\
\hline Canudos & 14 & 3,6 \\
\hline Guamá & 14 & 3,6 \\
\hline Sacramenta & 14 & 3,6 \\
\hline São Brás & 14 & 3,6 \\
\hline Icoaraci & 12 & 3,0 \\
\hline Terra Firme & 12 & 3,0 \\
\hline Batista Campos & 11 & 2,7 \\
\hline Coqueiro & 5 & 1,3 \\
\hline Cremação & 9 & 2,3 \\
\hline Val-de-Cans & 5 & 1,3 \\
\hline Campina & 4 & 1,0 \\
\hline Souza & 4 & 1,0 \\
\hline Outros bairros & 19 & 4,8 \\
\hline Não informado & 51 & 12,8 \\
\hline \multicolumn{3}{|l|}{ Ananindeva } \\
\hline Cidade Nova & 16 & 4,0 \\
\hline Coqueiro & 6 & 1,5 \\
\hline Guanabara & 5 & 1,3 \\
\hline Outros bairros & 14 & 3,6 \\
\hline Não informado & 6 & 1,5 \\
\hline \multicolumn{3}{|l|}{ Ocupação } \\
\hline Estudante & 88 & 22,2 \\
\hline Doméstica & 38 & 9,6 \\
\hline Menor sem ocupação & 33 & 8,3 \\
\hline Do lar & 24 & 6,1 \\
\hline Comerciante & 14 & 3,5 \\
\hline Professor & 9 & 2,3 \\
\hline Servidor público & 7 & 1,8 \\
\hline Motorista & 7 & 1,8 \\
\hline Pedreiro & 7 & 1,8 \\
\hline Aposentado & 6 & 1,5 \\
\hline Auxiliar de escritório & 4 & 1,0 \\
\hline Outras ocupações & 82 & 20,7 \\
\hline Não informado & 77 & 19,4 \\
\hline
\end{tabular}

N: Número amostral; \%: Frequência. 


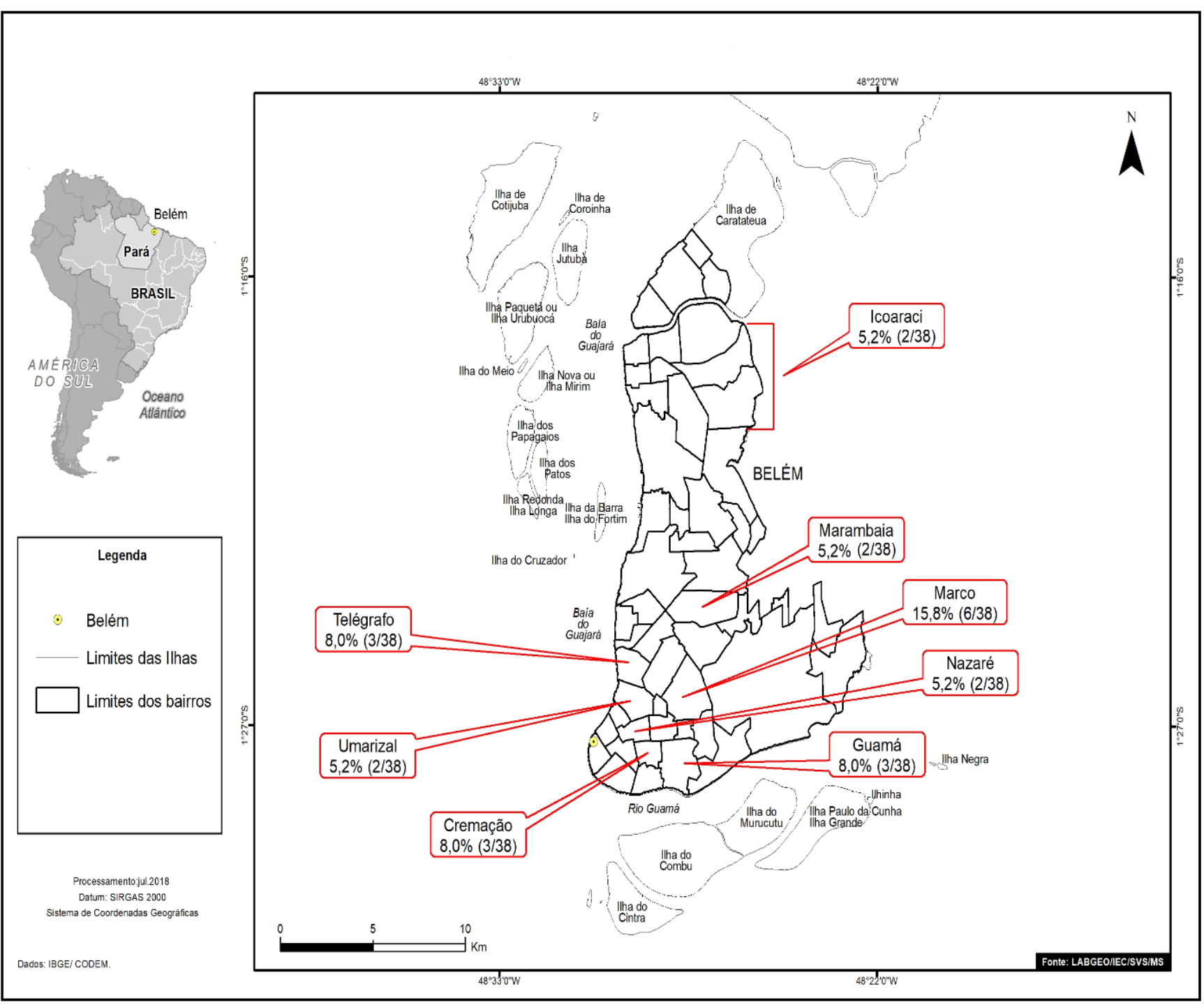

Fonte: Laboratório de Geoprocessamento (LabGeo/IEC/SVS/MS).

Figura 1 - Distribuição, por bairros de Belém, das amostras positivas para anticorpos anti-VHC de pacientes diagnosticados com HNANB atendidos na SAHEP/IEC, de 1982 a 1988, em Belém, estado do Pará, Brasil

Tabela 2 - Prevalência de anti-VHC+ e de VHC-RNA+, segundo sexo e faixa etária, em pacientes diagnosticados com HNANB atendidos na SAHEP/IEC, de 1982 a 1988, em Belém e Ananindeva, estado do Pará, Brasil

\begin{tabular}{|c|c|c|c|c|c|c|c|}
\hline Variáveis & $\begin{array}{c}\text { Examinados } \\
\mathrm{N}=396\end{array}$ & $\begin{array}{c}\text { Anti-VHC }+ \\
\mathrm{N}=43\end{array}$ & $\%$ & $\begin{array}{c}\text { p valor } \\
\alpha=0,05\end{array}$ & $\begin{array}{c}\text { VHC-RNA } \\
N=24\end{array}$ & $\%$ & $\begin{array}{c}\text { p valor } \\
\alpha=0,05\end{array}$ \\
\hline \multicolumn{8}{|l|}{ Sexo } \\
\hline Masculino & 219 & 22 & 10,0 & \multirow{2}{*}{$0.6775^{*}$} & 14 & 58,3 & \multirow{2}{*}{$0,7574^{\dagger}$} \\
\hline Feminino & 177 & 21 & 11,9 & & 10 & 41,7 & \\
\hline \multicolumn{8}{|l|}{ Faixa etária (anos) } \\
\hline$\leq 10$ & 63 & 3 & 4,8 & & - & - & \\
\hline $11-20$ & 75 & 6 & 8,0 & & 1 & 4,2 & \\
\hline $21-30$ & 111 & 15 & 13,5 & & 9 & 37,5 & \\
\hline $31-40$ & 57 & 8 & 14,0 & $0,2694^{\ddagger}$ & 5 & 20,8 & $0,5719^{\ddagger}$ \\
\hline $41-50$ & 40 & 3 & 7,5 & & 3 & 12,5 & \\
\hline $51-60$ & 23 & 6 & 26,1 & & 5 & 20,8 & \\
\hline$\geq 61$ & 27 & 2 & 7,4 & & 1 & 4,2 & \\
\hline
\end{tabular}

N: Número amostral; \%: Prevalência; Sinal convencional utilizado: - Dado numérico igual a zero, não resultante de arredondamento; ${ }^{*} \chi^{2}($ Yates $)=$ 0,$173 ;{ }^{\dagger} \chi^{2}$ (Yates) $=0,095 ; ~ ¥$ Teste G para amostras independentes. 


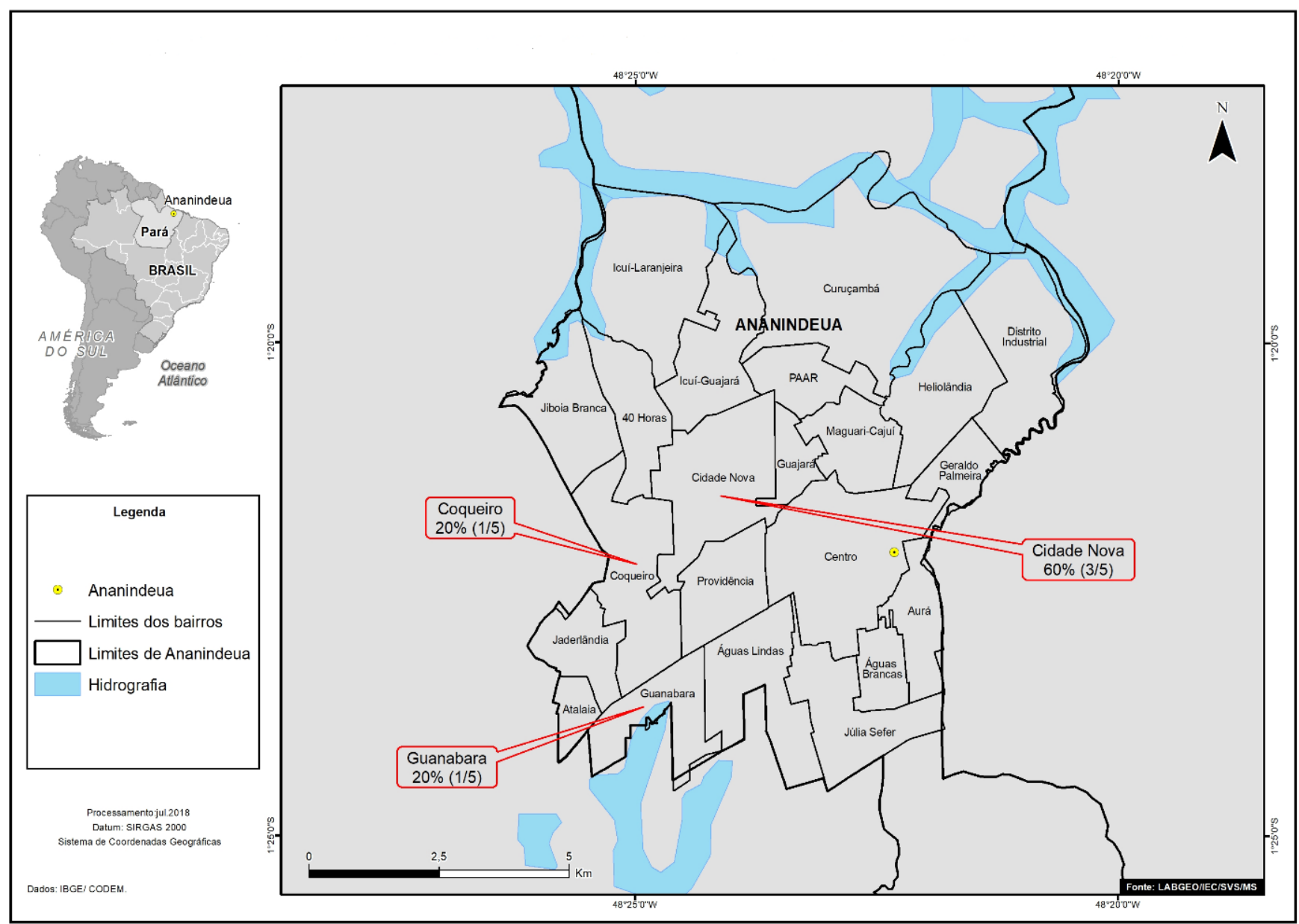

Fonte: LabGeo/IEC/SVS/MS

Figura 2 - Distribuição, por bairros de Ananindeua, das amostras positivas para anticorpos anti-VHC de pacientes diagnosticados com HNANB atendidos na SAHEP/IEC, de 1982 a 1988, em Ananindeua, estado do Pará, Brasil

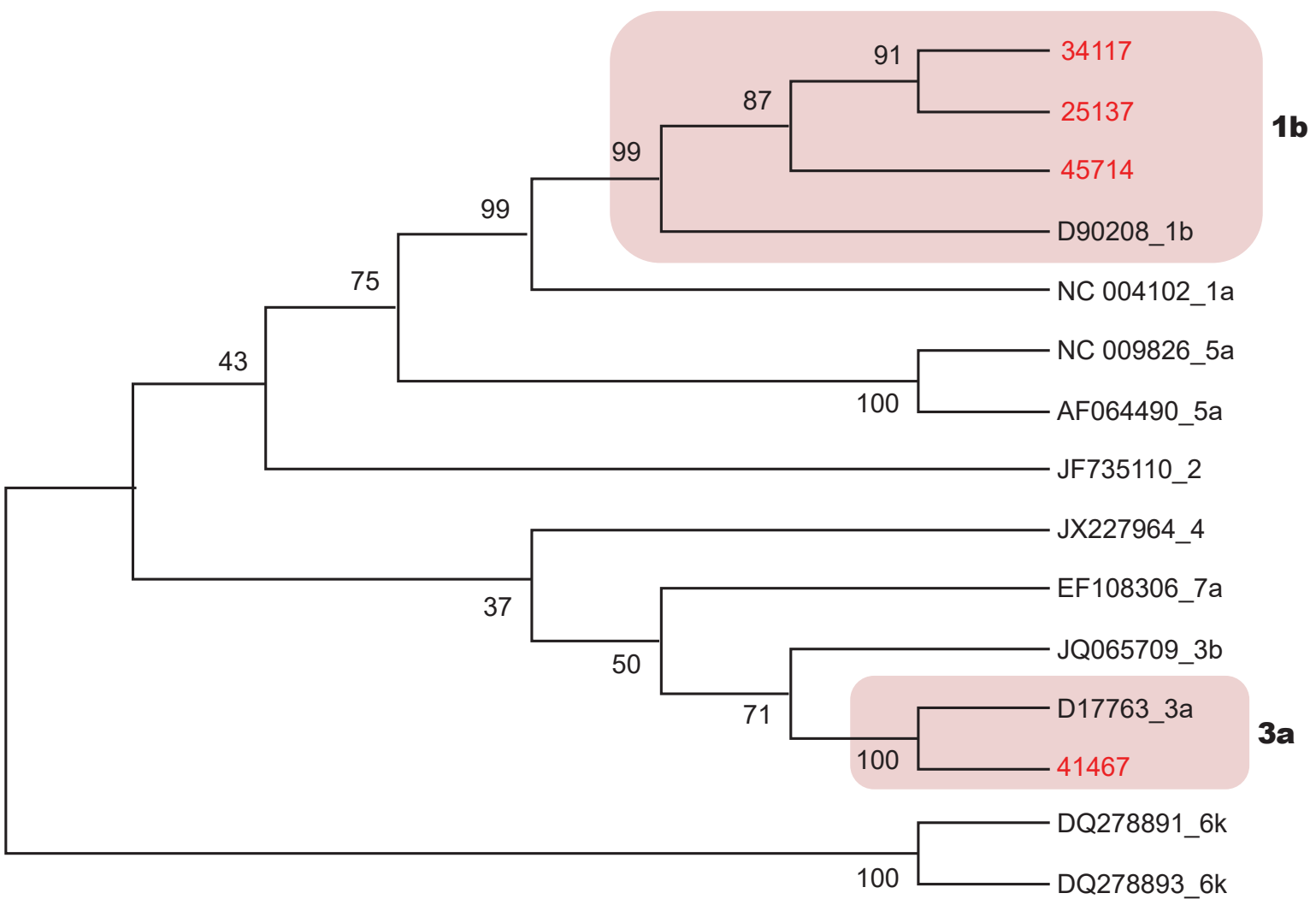

Sequências obtidas do GenBank estão identificadas com o número de acesso.

Figura 3 - Cladograma da região NS5B do VHC, inferida com método Neighbor-Joining (Kimura 2-parâmetros) no programa MEGA v7 


\begin{tabular}{|c|c|c|c|c|c|c|c|c|}
\hline \multirow{2}{*}{ Amostras (registro) } & \multirow{2}{*}{ Idade } & \multirow{2}{*}{ Sexo } & \multirow{2}{*}{$\begin{array}{l}\text { Procedência } \\
\text { Bairro (Belém) }\end{array}$} & \multirow{2}{*}{$\begin{array}{l}\log \\
(\mathrm{Ul} / \mathrm{mL})\end{array}$} & \multicolumn{2}{|c|}{ RT-PCR } & \multirow{2}{*}{ Genótipos } & \multirow{2}{*}{ Subtipos } \\
\hline & & & & & 5'UTR & NS5B & & \\
\hline 34117 & 18 & $\mathrm{~F}$ & $\mathrm{NI}$ & 4,23 & + & + & 1 & $1 b$ \\
\hline 41467 & 24 & M & $\mathrm{NI}$ & 2,80 & + & + & 3 & $3 a$ \\
\hline 25137 & 27 & $M$ & Marco & 3,35 & + & + & 1 & $1 b$ \\
\hline 43444 & 36 & M & Nazaré & 2,48 & + & - & 1 & \\
\hline 28387 & 44 & $\mathrm{~F}$ & Marco & 3,99 & + & - & 3 & \\
\hline 45714 & 52 & $\mathrm{~F}$ & Nazaré & 3,68 & + & + & 1 & $1 b$ \\
\hline 41064 & 54 & $\mathrm{~F}$ & Icoaraci & 2,82 & + & - & 1 & \\
\hline 17910 & 82 & M & Telégrafo & 2,69 & + & - & 1 & \\
\hline
\end{tabular}

NI: Não informado; +: Positivo; -: Negativo.

Quadro 1 - Características demográficas, carga viral e genótipos do VHC dos oito pacientes diagnosticados com HNANB com genótipos detectados, atendidos na SAHEP/IEC, de 1982 a 1988, em Belém, estado do Pará, Brasil

\section{DISCUSSÃO}

Estudos retrospectivos sobre a prevalência e a caracterização do VHC são importantes para a compreensão do seu comportamento na população e da sua dispersão à época em que o diagnóstico específico não estava disponível?. A despeito dos sensíveis e avançados métodos moleculares, disponíveis atualmente para o diagnóstico das hepatites virais, - longo período de armazenamento das amostras, ainda que criopreservadas $\left(-20^{\circ} \mathrm{C}\right.$ ), certamente induziu alterações em nível molecular capazes de prejudicar as análises laboratoriais, por se tratar de um vírus RNA extremamente suscetível à degradação, elevando esses circunstanciais prejuízos ${ }^{15}$. Não obstante, este estudo revelou resultados inéditos sobre a ocorrência de hepatite $\mathrm{C}$ na Amazônia brasileira no período analisado (1982 a 1988).

Antes da descoberta da hepatite $C$ e de seu agente etiológico, a incidência da HNANB nos Estados Unidos da América, na década de 1980, era considerada estável, apresentando uma média de 7,1 casos por 100.000 habitantes, segundo o Centers for Disease Control and Prevention que, por um período de sete anos (1982-1988), desenvolveu um estudo em quatro municípios-sentinela, utilizando amostras de pacientes com HNANB, coletadas entre 1985 e 1988, as quais foram testadas para anti-VHC, demonstrando $45 \%$ de positividade ${ }^{16}$.

Um estudo prospectivo, realizado na Espanha, entre 1978 e 1984, com 54 pacientes diagnosticados com HNANB pós-transfusional, detectou $85 \%$ de anticorpos para o $\mathrm{VHC}^{17}$. Em Paris, no período entre 1980 e 1989, $39,6 \%$ dos pacientes submetidos à hemodialise estavam infectados pelo $\mathrm{VHC}$ e esse hepatovírus foi responsável por $91 \%$ dos casos de $\mathrm{HNANB}^{18}$.

No Brasil, Focaccia et al. ${ }^{19}$ relataram prevalência de infecção pelo VHC de 1,4\% na população do município de São Paulo. Um estudo retrospectivo de reavaliação laboratorial da infecção pelo VHC, em amostras de 1990 a 1993, em Belém, descreveu prevalência de $62,6 \%$ para o anticorpo do $\mathrm{VHC}^{20}$. Valois et al. ${ }^{21}$ observaram 1,1\% de prevalência para o anti-VHC entre candidatos à doação de sangue na capital paraense.

A soroprevalência para o anti-VHC, na casuística estudada, foi de 10,9\%, superior ao observado por Fonseca et al. ${ }^{22}$, que encontraram positividade de $0,2 \%$ de anti-VHC, em estudo retrospectivo realizado no município de Manaus, estado do Amazonas, no período de 1989 a 1998, em pacientes com diagnóstico de hepatite aguda. Porém, similar ao relatado por Teixeira ${ }^{23}$, que observou positividade de $14,3 \%$ de anti-VHC em uma pesquisa de reavaliação clínico-laboratorial de casos notificados como HNANB, no período de 1994 a 1996, também em Belém e Ananindeua.

No presente estudo, a positividade para o anti-VHC foi semelhante entre os sexos, sendo mais elevada em adultos com idade entre 51 e 60 anos. Martins et al. ${ }^{24}$ sugeriram que a maior prevalência de hepatite $C$, observada após os 50 anos de idade, pode ser explicada pelo diagnóstico tardio de uma exposição ao VHC.

Em relação ao sexo e à faixa etária, um estudo de Santos et al. ${ }^{25}$, com pacientes que tiveram diagnóstico de HNANB, mostrou que todos os indivíduos reagentes para o anti-VHC eram do sexo masculino, com idade variando entre 27 e 36 anos. Simon et al. ${ }^{26}$, em estudo realizado na cidade de Paris, França, entre hemodialisados com HNANB, observaram que a idade média dos portadores de anti-VHC reagente era de 50 anos, sendo a maioria do sexo masculino. Valois et al. ${ }^{21}$, ao analisarem uma população de candidatos à doação de sangue, em Belém, encontraram o sexo masculino como predominante entre os casos de anti-VHC reagente, com maior prevalência na faixa etária entre 30 e 39 anos.

A abordagem da ocupação profissional é uma variável relevante em estudos epidemiológicos. Neste estudo, a ocupação profissional mostrou-se heterogênea, sobressaindo-se o grupo de estudantes. Morais e Oliveira ${ }^{27}$, em um estudo realizado no sudoeste baiano, entre 2003 e 2014, relataram prevalência de $0,96 \%$ de anti-VHC entre estudantes. 
$\mathrm{Na}$ presente pesquisa, todas as amostras eram de pacientes da zona urbana, dos municípios de Belém (a maioria) e Ananindeva. O bairro do Marco apresentou a maior prevalência de anti-VHC reagente entre os bairros de Belém; e a Cidade Nova, entre os bairros de Ananindeva, o que poderia ser explicado por se tratarem de bairros bastante populosos.

Apesar das limitações relacionadas ao tempo de armazenamento e acondicionamento das amostras de soro, foi possível detectar, no presente estudo, o RNA viral em 55,8\% dos 43 pacientes sororeagentes. Resultados inferiores foram relatados por Fonseca et al. ${ }^{28}$, que observaram uma prevalência de $5 \%$ de RNA viral detectado no estado do Amazonas, com amostras criopreservadas coletadas durante os anos de 1981 a 1986, de pacientes com HNANB aguda.

No estudo de Simon et al. ${ }^{26}$, com hemodialisados portadores de HNANB, realizado em Paris, 82,6\% (19/23) foram positivos para o RNA do VHC.

No Brasil, um estudo retrospectivo de reavaliação laboratorial da infecção pelo VHC, em amostras de dialisados, do período de 1990 a 1993, no município de Belém, descreveu 4,3\% de RNA viral detectado ${ }^{20}$.

Oliveira et al. ${ }^{29}$ demonstraram $62,5 \%$ de RNA viral em um estudo entre ribeirinhos do município de Cametá, no Pará. Freitas et al. ${ }^{30}$ relataram 5,3\% de detecção para o VHC-RNA em pacientes com anti-VHC reagente, em Belém. No estudo sobre os "Aspectos epidemiológicos da infecção pelo $\mathrm{VHC}$ em usuários de drogas não injetáveis no estado do Pará, leste da Amazônia", houve prevalência do RNA viral de $28 \%{ }^{31}$.

Os dados de detecção do VHC-RNA, do presente estudo, assemelham-se ao encontrado por Oliveira et al. ${ }^{29}$, com importante destaque para o fato de que as amostras de soro testadas na pesquisa citada, ao contrário das testadas na presente casuística, eram recém-coletadas. As variações encontradas, em diferentes estudos, podem ser explicadas pelas diferenças entre os grupos estudados e/ou amostras criopreservadas, e pelo tempo decorrido entre a coleta e a realização dos testes.

Além da importância para a filogenia, a genotipagem do VHC é um fator importante para o manejo de indivíduos infectados e para fins epidemiológicos, indica a via de aquisição e afeta o resultado clínico e a resposta ao tratamento ${ }^{32,33}$. $\bigcirc$ genótipo 1 , subtipo $1 \mathrm{~b}$, é mais resistente a determinadas terapias, e o genótipo 3 , subtipo $3 a$, está expressivamente associado às formas mais agressivas da doença ${ }^{32}$.

A genotipagem do $\mathrm{VHC}$ deste estudo foi realizada por sequenciamento das regiões 5'UTR e NS5B. Foi possível a genotipagem em oito dos 24 RNAs detectados, sendo a maioria genotipada na região 5'UTR. Dois genótipos (1 e 3) foram identificados nas duas regiões, nas mesmas amostras de soro, e dois subtipos (1b e 3a) foram caracterizados na região NS5B.

A 5'UTR é altamente conservada; consequentemente, a região de anelamento do primer, nessa região, é bem

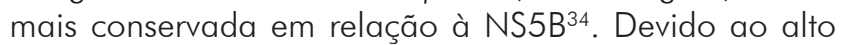
nível de conservação e sensibilidade da 5'UTR, essa região tem sido mais utilizada por laboratórios clínicos para genotipagem do $\mathrm{VHC}^{35}$. Assim, tais características podem explicar a detecção de mais genótipos na região 5'UTR do que na NS5B pesquisadas.

Não foi possível a discriminação de subtipos dentro dos genótipos detectados na região 5'UTR. A região 5'UTR, ao contrário da NS5B, devido seu alto nível de conservação, não possui variação suficiente para discriminar as classificações do VHC em nível de subtipo viral $^{34,35,36}$. Assim, as árvores filogenéticas da 5'UTR são menos capazes de agrupar subtipos do mesmo genótipo em clados do que árvores de sequências da NS5B, independentemente do método utilizado para inferência filogenética ${ }^{34}$.

Os genótipos 1 e 3 do VHC são a causa mais comum de infecções ao redor do mundo ${ }^{1,37}$. No Brasil, o genótipo 1 é considerado o mais prevalente, seguido do genótipo 3 e do genótipo $2^{1,12,37}$. Dentre as regiões do Brasil, a Região Norte apresenta a maior frequência de genótipo 1 (51,7\% a 74,1\%); a Região Centro-Oeste, de genótipo 2 (1 1,4\%); a Região Sul, de genótipo 3 (43,2\%); e na Região Sudeste, no estado de São Paulo, foram descritos os genótipos 4 e 5 , raramente encontrados ${ }^{12}$.

Perone et al. ${ }^{38}$ realizaram um estudo com pacientes portadores de hepatite C crônica, atendidos nos Centros de Referência em Hepatites Virais de Belo Horizonte, estado de Minas Gerais, entre 2002 e 2006, e observaram alta prevalência do genótipo $1(78,4 \%)$ e do genótipo 3 (17,9\%). Oliveira et al. ${ }^{39}$ relataram detecção de 77,1\% para o genótipo 1 e 19,82\% para o genótipo 3 em estudo realizado em um hospital de referência em doenças infectocontagiosas no estado do Goiás.

Nesta casuística, foi possível a genotipagem de um terço das amostras positivas para VHC-RNA, com predominância do genótipo 1, assemelhando-se ao estudo de Sawada et al. ${ }^{36}$, que concluiu que, na distribuição do VHC em diferentes categorias de exposição no Pará, há predominância do genótipo 1 .

A distribuição de genótipos identificados na presente pesquisa foi semelhante ao encontrado por Baia ${ }^{20}$, que descreveu detecção de $73 \%$ para o genótipo 1 e 24,3\% para o genótipo 3 em estudo retrospectivo entre dialisados, no período de 1990 a 1993, em Belém.

Os dados do estudo atual também foram semelhantes a achados de outros autores na Região Norte, demonstrando a importância dos genótipos 1 e 3 na epidemiologia dessa virose: Campiotto et al. ${ }^{12}$ descreveram detecção de 74,1\% para o genótipo 1 e 24,7\% para o genótipo 3 na Região Norte; Araújo et al. ${ }^{40}$ encontraram prevalência de $76,1 \%$ para 0 genótipo 1 e 19,6\% para o genótipo 3 em pacientes com hepatite crônica no estado do Amazonas; Oliveira et al. ${ }^{39}$ observaram $76,9 \%$ de genótipo 1 e 23,1\% de genótipo 3 em usuários de drogas não injetáveis no Pará; Guimarães et al. ${ }^{41}$ detectaram 72,4\% de genótipo 1 e 23,3\% de genótipo 3 na população em geral, no estado do Pará, e descreveram prevalência de 76,7\% para o genótipo 1 e 20,7\% para o genótipo 3 na Região Metropolitana de Belém. 
Um estudo de caráter retrospectivo, realizado no Amazonas, também analisou amostras de soro criopreservadas a $-70^{\circ} \mathrm{C}$, coletadas no período de 1981 a 1986, para posterior análise do $\mathrm{VHC}^{28}$. Outro estudo, também de caráter retrospectivo, foi realizado por Baia ${ }^{20}$ em amostras acondicionadas em biobanco $\left(-20^{\circ} \mathrm{C}\right)$ por mais de 20 anos. Esses estudos corroboram com a presente pesquisa, destacando a importância do uso de biobancos institucionais na pesquisa em saúde.

\section{CONCLUSÃO}

Apesar das limitações do estudo, pelo longo tempo de armazenamento das amostras (três décadas), foi possível detectar 10,9\% de anticorpos anti-VHC e caracterizar o $\mathrm{VHC}$ em soros oriundos de biobanco, revelando a circulação à época de pelo menos dois genótipos e dois subtipos do vírus: a) o genótipo 1, detectado na maioria das amostras genotipadas e, na atualidade, exibindo maior resistência a fármacos que os demais genótipos conhecidos; e b) o genótipo 3, menos frequente na amostra do estudo, mas, na atualidade, associado a maior virulência.

Concluiu-se que a análise de amostras do biobanco permitiu a identificação de linhagens do $\mathrm{VHC}$, podendo favorecer estudos futuros com o objetivo de elucidar aspectos evolutivos associados à resistência e virulência desse patógeno.

Sugere-se que as instituições avaliem qual seria a melhor forma de acondicionamento de amostras de soro, a exemplo de congelamento a temperaturas mais baixas, alíquotas, liofilização, etc.; bem como, o custo-benefício da modernização desses procedimentos nos biobancos institucionais visando à pesquisa em saúde, pela extrema relevância para estudos presentes e futuros.

\section{AGRADECIMENTOS}

A todos os que participaram tornando possível a realização do estudo; e aos servidores da SAHEP/IEC/SVS/MS, pela colaboração para o desenvolvimento e revisão do artigo.

\section{APOIO FINANCEIRO}

suporte financeiro para a execução do trabalho foi do IEC/SVS/MS.

\section{CONFLITOS DE INTERESSES}

Não existem conflitos de interesses em relação à pesquisa apresentada.

\section{CONTRIBUIÇÃO DOS AUTORES}

Kemere Marques Vieira Barbosa, Alex Junior Souza de Souza, Heloisa Marceliano Nunes, Lourdes Maria Garcez e Manoel do Carmo Pereira Soares contribuíram com a idealização do estudo, a análise e a interpretação dos dados e com a redação do manuscrito. Luiz Vinicius Leão Moreira contribuiu com a realização dos exames, a construção do banco de dados, o levantamento bibliográfico e a revisão crítica do manuscrito. Candida Maria Abrahão de Oliveira auxiliou no levantamento bibliográfico, participou da sistematização e revisão crítica do manuscrito. Os autores aprovaram o manuscrito e declaram serem responsáveis por todos os aspectos da pesquisa, garantindo sua precisão e integridade.

\section{REFERÊNCIAS}

1 Polaris Observatory HCV Collaborators. Global prevalence and genotype distribution of hepatitis $\mathrm{C}$ virus infection in 2015: a modelling study. Lancet Gastroenterol Hepatol. 2017 Mar;2(3):161-76.

2 European Association for the Study of the Liver. EASL recommendations on treatment of hepatitis C 2018. J Hepatol. 2018 Aug;69(2):461-511.

3 Sociedade Brasileira de Hepatologia. Sociedade Brasileira de Infectologia. Consenso. Recomendações das Sociedades Brasileiras de Hepatologia (SBH) e Infectologia (SBI) para o tratamento da hepatite C no Brasil com novos medicamentos antivirais de ação direta (DAAs). Braz J Infect Dis. 2016 mar;20(2 Supl 1):S2-7.

4 Ministério da Saúde (BR). Secretaria de Vigilância em Saúde. Departamento de Vigilância, Prevenção e Controle das IST, do HIV/Aids e das Hepatites Virais. Manual Técnico para o Diagnóstico das Hepatites Virais. 2. ed. Brasília: Ministério da Saúde; 2018.
5 Viana DR, Veloso NM, Carvelho Neto O, Papacota NG, Nunes GM, Guedes VR. Hepatite B e C: diagnóstico e tratamento. Rev Patol Tocantins. 2017 set;4(3):73-9.

6 Pawlotsky JM, Feld JJ, Zeuzem S, Hoofnagle $\mathrm{JH}$. From non-A, non-B hepatitis to hepatitis $C$ virus cure. J Hepatol. 2015 Apr;62(1 Suppl): S87-99.

7 Choo QL, Kuo G, Weiner AJ, Overby LR, Bradley DW, Houghton M. Isolation of a cDNA clone derived from a blood-borne non-A, non-B viral hepatitis genome. Science. 1989 Apr;244(4902):359-62.

8 International Committee on Taxonomy of Viruses. Virus taxonomy: 2017 release [Internet]. Birmingham (AL): ICTV; 2017 [cited 2017 Jun 17]. Available from: https://talk.ictvonline.org/taxonomy/.

9 Conte VP. Hepatite crônica por vírus C. Parte 1: considerações gerais. Arq Gastroenterol. 2000 jul-set;37(3): 187-94. 
10 Morice Y, Roulot D, Grando V, Stirnemann J, Gault $E$, Jeantils $V$, et al. Phylogenetic analyses confirm the high prevalence of hepatitis $\mathrm{C}$ virus (HCV) type 4 in the Seine-Saint-Denis district (France) and indicate seven different HCV-4 subtypes linked to two different epidemiological patterns. J Gen Virol. 2001 May;82(P+ 5):1001-12.

11 Sandres-Sauné K, Deny P, Pasquier C, Thibaut V, Duverlie G, lzopet J. Determining hepatitis C genotype by analyzing the sequence of the NS5b region. J Virol Methods. 2003 May;109(2): 187-93.

12 Campiotto S, Pinho JR, Carrilho FJ, Silva LC, Souto FJ, Spinelli V, et al. Geographic distribution of hepatitis $C$ virus genotypes in Brazil. Braz J Med Biol Res. 2005 Jan;38(1):41-9.

13 Ayres M, Ayres Jr M, Ayres DL, Santos AS. BioEstat 5.0: aplicações estatísticas nas áreas das ciências biológicas e médicas. Belém: Sociedade Civil Mamirauá; 2007. 364 p.

14 Brasil. Ministério da Saúde. Resolução n 466, de 12 de dezembro de 2012. Aprova normas regulamentadoras de pesquisas envolvendo seres humanos. Diário Oficial da União, Brasília (DF), 2013 jun 12; Seção 1:59.

15 Moreau de Gerbehaye Al, Bodéus M, Robert A, Horsmans Y, Goubau P. Stable hepatitis C virus RNA detection by RT-PCR during four days storage. BMC Infect Dis. 2002 Oct;2:22.

16 Alter MJ, Hadler SC, Judson FN, Mares A, Alexander WJ, Hu PY, et al. Risk factors for acute non-A, non-B hepatitis in the United States and association with hepatitis C virus infection. JAMA. 1990 Nov;264(17):2231-5.

17 Esteban JI, Viladomiu L, Gonzalez A, Roget M, Genescà J, Esteban R, et al. Hepatitis C virus antibodies among risk groups in Spain. Lancet. 1989 Aug;334(8658):294-7.

18 Alter MJ. HCV routes of transmission: what goes around comes around. Semin Liver Dis. 2011 Nov;31 (4):340-6.

19 Focaccia R, Conceição OJ, Sette H Jr, Sabino E, Bassit L, Nitrini DR, et al. Estimated prevalence of viral hepatitis in the general population of the Municipality of São Paulo, measured by a serologic survey of a stratified, randomized and residence-based population. Braz J Infect Dis. 1998 Dec;2(6):269-84.

20 Baia KSM. Reavaliação laboratorial da infecção pelo vírus da hepatite $\mathrm{C}$ em dialisados atendidos no período de 1990-1993, Belém, Pará, Brasil [Monografia]. Belém (PA): Universidade Federal do Pará, Faculdade de Medicina e Cirurgia do Pará; 2013. 58 p.
21 Valois RC, Maradei-Pereira LMC, Crescente JAB, Oliveira-Filho $A B$, Lemos JAR. VHC infection through perforating and cutting material among candidates for blood donation in Belém, Brazilian Amazon. Rev Inst Med Trop S Paulo. 2014 Nov-Dec;56(6):51 1-5.

22 Fonseca JCF, Brasil LM. Infecção pelo vírus da hepatite $C$ na região Amazônica brasileira. Rev Soc Bras Med Trop. 2004;37(Supl 2):1-8.

23 Teixeira LSC. Hepatite não-A, não-B: reavaliação clínico-laboratorial de casos notificados nos municípios de Belém e Ananindeua, estado do Pará [Monografia]. Belém (PA): Universidade Federal do Pará, Centro de Ciências da Saúde; 1997. 81 p.

24 Martins T, Narciso-Schiavon JL, Schiavon LL. Epidemiologia da infecção pelo vírus da hepatite $C$. Rev Assoc Med Bras. 2011 jan-fev;57(1):107-12.

25 Santos A, Carvalho A, Bento D, Sá R, Tomaz J, Rodrigues $V$, et al. Epidemiologia da hepatite $C$ na região centro de Portugal - prevalência do anti-VHC na população do Distrito de Coimbra. Acta Med Port. 1993;6:567-72.

26 Simon N, Couroucé AM, Lemarrec N, Trépo C, Ducamp S. A twelve year natural history of hepatitis $C$ virus infection in hemodialyzed patients. Kidney Int. 1994 Aug;46(2):504-11.

27 Morais MTM, Oliveira TJ. Perfil epidemiológico e sóciodemográfico de portadores de hepatite $\mathrm{C}$ de um município do sudoeste baiano. Rev Saude.Com. 2015 jun; 11 (2):137-46.

28 Fonseca JCF, Brasil L, Fay F, Castilho M, Botelho R, Borborema $C$, et al. Prevalência da infecção pelo vírus da hepatite $\mathrm{C}(\mathrm{VHC})$ e da hepatite $\mathrm{E}(\mathrm{VHE})$ em pacientes com hepatite aguda N-A, N-B, N-D. Arch Argent Enferm Apar Dig. 1996;10:90.

29 Oliveira CSF, Silva AV, Santos KN, Fecury AA, Almeida MKC, Fernandes $\mathrm{AP}$, et al. Infecção pelo vírus da hepatite $\mathrm{B}$ e $\mathrm{C}$ em ribeirinhos da Amazônia brasileira. Rev Soc Bras Med Trop. 2011 set-out;44(5):546-50.

30 Freitas MJR, Fecury AA, Almeida MKC, Freitas AS, Guimarães VS, Silva AM, et al. Prevalence of hepatitis $C$ virus infection and genotypes in patient with chronic kidney disease undergoing hemodialysis. J Med Virol. 2013 Oct;85(10):1741-5.

31 Oliveira-Filho AB, Sawada L, Pinto LC, Locks D, Bahia SL, Castro JA, et al. Epidemiological aspects of $\mathrm{HCV}$ infection in non-injecting drug users in the Brazilian state of Pará, eastern Amazon. Virol J. 2014 Feb; 11 (38).

32 Kermani FR, Sharifi Z, Ferdowsian F, Paz Z, Zamanian $M$. Distribution of hepatitis $C$ virus genotypes among chronic infected injecting drug users in Tehran, Iran. Jundishapur J Microbiol. 2013 Feb;6(3):265-8. 
33 Moosavy SH, Davoodian P, Nazarnezhad MA, Nejatizaheh A, Eftekhar E, Mahboobi $H$. Epidemiology, transmission, diagnosis, and outcome of hepatitis $\mathrm{C}$ virus infection. Electron Physician. 2017 Oct;9(10):5646-56

34 Hraber PT, Fischer W, Bruno WJ, Leitner T, Kuiken C. Comparative analysis of hepatitis $C$ virus phylogenies from coding and non-coding regions: the $5^{\prime}$ untranslated region (UTR) fails to classify subtypes. Virol J. 2006 Dec;3:103.

35 Murphy DG, Willems B, Deschênes $M$, Hilzenrat N, Mousseau R, Sabbah $S$. Use of sequence analysis of the NS5B region for routine genotyping of hepatitis $C$ virus with reference to $C / E l$ and $5^{\prime}$ untranslated region sequences. J Clin Microbiol. 2007 Apr;45(4): $1102-12$

36 Sawada L, Pinheiro AC, Locks D, Pimenta AS, Rezende PR, Crespo DM, et al. Distribution of hepatitis $C$ virus genotypes among different exposure categories in the State of Pará, Brazilian Amazon. Rev Soc Bras Med Trop. 2011 Jan-Feb;44(1):8-12.

37 Petruzziello A, Marigliano S, Loquercio G, Cozzolino A, Cacciapuoti C. Global epidemiology of hepatitis $C$ virus infection: an up-date of the distribution and circulation of hepatitis C virus genotypes. World J Gastroenterol. 2016 Sep;22(34):7824-40.
38 Perone C, Del Castillo DM, Pereira GL, Carvalho $\mathrm{NO}$, Januário JN, Teixeira R. Alta prevalência do genótipo 1 em portadores de hepatite $C$ crônica em Belo Horizonte, MG. Rev Soc Bras Med Trop. 2008 mai-jun;4 1 (3):238-42.

39 Oliveira TJB, Reis LAP, Barreto LSLO, Gomes JG, Manrique EJC. Perfil epidemiológico dos casos de hepatite $C$ em um hospital de referência em doenças infectocontagiosas no estado de Goiás, Brasil. Rev Pan-Amaz Saude. 2018 mar;9(1): $51-7$.

40 Araújo AR, Almeida CM, Fraporti L, Garcia N, Lima TA, Maia LP, et al. Caracterização do vírus da hepatite $C$ em pacientes com hepatite crônica: genótipos no Estado do Amazonas, Brasil. Rev Soc Bras Med Trop. 2011 set-out;44(5):638-40.

41 Guimarães VS, Melo TG, Ferreira RCD, Almeida SF, Martins LC. Prevalence of hepatitis C virus genotypes in the State of Pará, Brazil. Rev Soc Bras Med Trop. 2018 Jul-Aug;51(4): 508-12. 